Culture et histoire dans l'espace roman

Crise(s) dans le monde ibérique et ibéro-américain

\title{
Los fantasmas de Hamlet
}

Teatralidad, escritura y crisis en Aire de Dylan (2012), de Enrique VilaMatas

\section{Cristina Oñoro Otero}

\section{(2) OpenEdition}

12 Journals

Edición electrónica

URL: https://journals.openedition.org/cher/3787

DOI: $10.4000 /$ cher.3787

ISSN: 2803-5992

\section{Editor}

Presses universitaires de Strasbourg

\section{Edición impresa}

Fecha de publicación: 1 diciembre 2015

Paginación: 163-174

ISBN: 978-2-86820-913-9

ISSN: 1968-035X

\section{Referencia electrónica}

Cristina Oñoro Otero, «Los fantasmas de Hamlet», reCHERches [En línea], 15 | 2015, Publicado el 01 diciembre 2021, consultado el 15 diciembre 2021. URL: http://journals.openedition.org/cher/3787 ; DOI: https://doi.org/10.4000/cher.3787 


\title{
Los fantasmas de Hamlet. Teatralidad, escritura y crisis en Aire de Dylan (2012), de Enrique Vila-Matas
}

\author{
Cristina OÑoro Otero \\ Université de Strasbourg - EA4376-C.H.E.R.
}

\section{Vivir en las preguntas}

Para comenzar, a modo de apertura, querría formular un interrogante o, si se quiere, un problema, una cuestión en el sentido que le otorgan los anglosajones a esta palabra. Empezar planteando una pregunta parecería lo más adecuado si queremos convocar, como haremos aquí, los fantasmas de Hamlet, pues precisamente la palabra question es una de las que más obsesivamente aparecen en la obra maestra de William Shakespeare. De hecho, tal es la obsesión de Hamlet por las preguntas y los problemas -especialmente por los que atañen al mundo del teatro- que Vicente Molina Foix llega a definir al Príncipe de Dinamarca como «una cabeza discursiva y pensante, un prototipo del temperamento artístico empeñado en "vivir las preguntas"» (2012: 10).

Pero ¿cuál es el interrogante al que me refiero?

Se trata de una pregunta que plantea Enrique Vila-Matas en Aire de Dylan, un libro que no por casualidad se encuentra atravesado por el personaje de Hamlet y sus fantasmas: «¿La vida es una farsa que todos debemos representar?» (2012: 313).

Esta «metáfora del teatro» que emplea Vila-Matas en realidad es muy antigua y sus orígenes se confunden con los de la propia literatura occidental ${ }^{1}$, pues ya

1 Por razones de espacio aquí no puedo detenerme en el estudio del origen y la evolución de las metáforas del teatro. Para ello, remito a la obra seminal de Ernst Robert Curtius Literatura europea y Edad Media Latina donde se dedica un apartado a esta cuestión (1999: 203-211). 
la encontramos en los Diálogos de Platón y en la obra de los escritores estoicos. A partir de los siglos dieciséis y diecisiete, reaparece con fuerza en las literaturas europeas y con ella emerge la visión barroca del mundo: un mundo en el que se vuelve imposible distinguir lo real de sus apariencias o, lo que es lo mismo, lo real de sus fantasmas.

La comprensión de la vida como una representación teatral es parte de una tópica más amplia -el mundo como teatro- que también encierra la imagen del hombre como un títere, actor o marioneta ${ }^{2}$. Se trata de una metáfora de naturaleza cosmológico-religiosa, pues, según el esquema analógico que emplean autores como Ronsard, Shakespeare o Calderón, el papel de dramaturgo principal lo desempeñan la Fortuna ${ }^{3}$ o Dios ${ }^{4}$, quienes a menudo aparecen también como espectadores privilegiados del destino de los humanos. Como apunta Patrice Pavis, estas metáforas teológico-teatrales con el tiempo dan paso a la forma lúdica del teatro dentro del teatro donde la representación se vuelve consciente de sí misma y se auto-representa (Pavis 2006: 365).

Las viejas metáforas del teatro han cobrado nueva vida en la posmodernidad. En efecto, para los escritores de la segunda mitad del siglo veinte, como Enrique Vila-Matas, el teatro vuelve a ser una herramienta propicia para pensar el mundo y nuestra forma de habitarlo ${ }^{5}$. La idea esencial que late detrás de la metáfora, a saber, que en esta vida cada uno de nosotros lleva una máscara y representa un papel, es de hecho muy afín a la sensibilidad posmoderna, pues esta se

2 Bajo esta forma la encontramos en los textos de Platón: «Figurémonos que cada uno de nosotros, representantes de los seres vivos, es un juguete animado que los dioses fabricaron, ya sea por divertirse, ya porque les haya movido un propósito serio» (Las Leyes, I, 644 d-e. Citado en Curtius 1999: 203). «El hombre [...] no es sino un juguete animado, hecho por la mano de Dios, y esto es, en verdad, lo mejor que hay en él.» (Las Leyes, VII, 803 d-e. Citado en Curtius 1999: 203).

3 Así podemos leerlo en un texto de Ronsard citado por Curtius (1999: 207): «Ici la Comédie apparaît un exemple/ où chacun de son fait les actions contemple: /le monde est un théâtre, et les hommes acteurs./ La Fortune qui est maîtresse de la scène/ apprête les habits, et de la vie humaine/ les cieux et les destins en sont les spectateurs».

4 Como señala Curtius, Calderón es el primer autor que convierte el theatrum mundi, dirigido por Dios, en asunto de drama religioso. Toda su obra tiene esta dimensión de un teatro universal, lo que queda patente, sin ir más lejos, en los fragmentos de La vida es sueño que cita el propio Curtius: «Salga a la anchurosa plaza/ del gran teatro del mundo/ este valor sin segundo [...] El dosel de la jura, reducido/ a segunda intención, a horror segundo,/ teatro funesto es, donde importuna/ representa tragedias la fortuna.» (citado en Curtius 1999: 208).

5 Entre los ejemplos de novelas publicadas en las últimas décadas en las que se aborda el mundo del teatro pueden citarse Tocarnos la cara (1995), de Belén Gopegui, Los dos Luises (2000), de Luis Magrinyá o Comedia con fantasmas (2002), de Marcos Ordóñez. Y, fuera de las fronteras españolas, La spettatrice (1995), de Paola Capriolo o Le quatrième mur (2013), de Sorj Chalandon. 
caracteriza, precisamente, por la sistemática puesta en cuestión de todo aquello que se considere «natural»o «auténtico» 6 .

En las siguientes páginas me propongo estudiar el modo en que Vila-Matas recurre a las metáforas del teatro y al imaginario teatral para reflejar un mundo y un sujeto en crisis. Para ello, primero dedicaré un apartado a la crisis del sujeto moderno, problemática posmoderna que se encuentra presente en toda su obra; y, después, pasaré a revisar cómo, en Aire de Dylan, el teatro se convierte en un instrumento privilegiado para pensar dicha crisis. Como veremos, en esta novela del siglo veintiuno, Vila-Matas establece un intenso diálogo con Hamlet, ese Príncipe de las preguntas enigmáticas e intempestivas que también empleó el teatro como herramienta para pensar el mundo.

¿Cómo haremos para desaparecer?

La crisis del sujeto moderno es uno de los temas que vertebran la obra narrativa y ensayística de Enrique Vila-Matas. Así, la encontramos planteada tras una serie de preguntas que obsesivamente atraviesan sus textos: ¿quién escribe? y ¿desde dónde lo hace? Interrogantes que pueden resumirse en uno solo: ¿qué es un autor? En este sentido, Vila-Matas hace teoría dentro de la literatura y literatura al hilo de la reflexión teórica. Su universo es, pues, uno de esos casos en los que, como apuntan Gilles Deleuze y Felix Guattari en ¿Qué es filosofía? (1993), el plano de los conceptos, que es el propio de la filosofía, y el de los afectos, que sería el del arte, se entrecruzan y solapan. Vila-Matas utiliza formas artísticas para pensar problemas filosóficos -como la crisis del sujeto- y estos problemas le sirven, a su vez, para construir su obra narrativa.

Como señalan autorizados teóricos del posmodernismo como Fredric Jameson (1991) o Brian McHale (1996) la crisis del sujeto es uno de los conceptos clave que articulan la poética posmoderna. No obstante, conviene precisar que se trata de una idea que, a fuerza de repetirse de mil maneras distintas, se ha visto tergiversada considerablemente: olvidando que abre un horizonte distinto desde el que pensar la subjetividad, a menudo se ha interpretado esta crisis del sujeto como el triunfo del relativismo, es decir, como una nueva formulación del viejo hombre sofista que es medida de todas las cosas. Tropezamos, pues, con un obstáculo que la filósofa Teresa Oñate ya preveía en un artículo de los años ochenta: la tensa convivencia del pensamiento posmoderno, que intentaría pensar y vivir más allá de la categoría de sujeto, con una hipermodernidad vigente $y$ oficial -como la que, por ejemplo, retrata Gilles Lipovetsky en sus escritos ${ }^{7}$

6 La crítica Linda Hutcheon halla la especificidad del posmodernismo en este tenaz y contradictorio desafío crítico que surge al remarcar el carácter cultural de nociones que se consideran naturales (Hutcheon 1990).

7 Para este sociólogo francés la disolución de las estructuras identitarias fuertes, como la de sujeto, tiene un efecto paradójico: la proliferación del «yo». Tal y como explica en su libro La era del vacio (2004), los cambios que han transformado profundamente al individuo contemporáneo pueden interpretarse como síntoma de una nueva fase del individualismo occidental, a la que denomina "proceso de personalización». Este 
que instala el «yo» en el lugar que la metafísica tradicional reservaba al «Diosfundamento».

En un interesante artículo, Francisco Jarauta (1986) analiza este paso de la razón clásica al saber de la precariedad propio de la posmodernidad, que él sitúa en el pensamiento nietzscheano. En su opinión, la estructura teorética tradicional que Nietzsche pone en cuestión es la de totalidad, y su consecuencia inmediata es la crisis del sujeto trascendental. La idea metafísica de «todo», que permitía establecer un discurso de la totalidad, pierde su poder de ordenar y dar sentido a la multiplicidad de lo real. Así, el gesto cartesiano-kantiano de fundamentación de la verdad que había dado lugar a un sujeto constituyente cede paso a un sujeto constituido incapaz ya de ordenar y representar la naturaleza según una aspiración universal de verdad. A partir de la crisis del concepto de verdad aparece un "sujeto finito, empírico, condicionado», muy alejado del sujeto fuerte trascendental, al que le resulta imposible establecer «lo incondicionado, lo absoluto, lo incontrovertible» (Jarauta 1986: 53). De ahí que sea en el pensamiento nietzscheano donde se disuelva el proyecto moderno:

Este presuponía una subjetividad que correspondiera a la idea de mundo como totalidad, y como condición para la fundación de un concepto de verdad. Esta pretensión de verdad resulta [...] un sueño, que hasta el más serio de los restauradores racionales -hablo de Husserl- considera ya soñado. (Jarauta 1986: 54)

¿Cómo se manifiesta literariamente esta crisis del sujeto moderno en la obra de Enrique Vila-Matas? Podemos enumerar distintas estrategias. En primer lugar, cabe mencionar la preferencia por narradores intrusivos, irónicos y poco fiables, como los de Jorge Luis Borges o Vladimir Nabokov, que se expresan a través de citas eruditas y hacen un uso fragmentario de la memoria. Un narrador, pues, que se encontraría en las antípodas del narrador omnisciente decimonónico que sí era capaz de construir un mundo de ficción total y completo. Así, por ejemplo, en Mujer en el espejo contemplando el paisaje (1973) o en La asesina ilustrada (1977), dos de sus primeras novelas, el narrador se multiplica a partir de numerosas voces, y utiliza juegos de espejos y estructuras recursivas. Se trata, pues, de una voz narrativa dividida y fragmentaria.

Pero, ¿cuál es el problema del sujeto para Vila-Matas? El problema es precisamente ése: su naturaleza problemática. Su estatuto es el de una cuestión hamletiana que hay que resolver. Así ocurre, por ejemplo, en Historia abreviada de la literatura portátil (1985), pues toda la obra está recorrida por nuevas preguntas: ¿qué relación existe entre una obra de arte y su productor?, ¿es su proyección mental o, por el contrario, el artista y su obra se encuentran absolutamente desconectados? Como vemos, la crisis del sujeto afecta inmediatamente al origen de la significación, lo que acarrea nuevos interrogantes: ¿quién produce

proceso de personalización o individualismo avanzado vendría propiciado por los valores imperantes en el mundo contemporáneo: la seducción, el relativismo en las costumbres, el narcisismo, el consumo, la ausencia de valores fuertes... 
significado? ¿Cómo se puede re-significar una obra? ¿En cuántos contextos puede reinsertarse un texto sin que cambie completamente su sentido?

En otras obras, como Extraña forma de vida (1997), el problema del sujeto - ¿quién habla?, ¿quién mira?-, se relaciona de forma explícita con la muerte de Dios. Si éste ha desaparecido, como leemos en los textos de Maurice Blanchot y de Roland Barthes que Vila-Matas cita a menudo ${ }^{8}$, es imposible que la obra de arte presente una imagen total del universo, pues ya no existe una instancia exterior que pueda dotarlo de sentido:

Desde que Dios no existe, desde que no creemos que alguien nos observa, nuestra vida carece de finalidad. Mi hermano Máximo me hizo ver un día que el hombre de otros siglos, que conservaba el sentido religioso, creía que una divinidad le estaba contemplando, y por consiguiente -como un futbolista ante la mirada rigurosa de ese gran espía, de ese ser superior que es el entrenador- intentaba dar una coherencia a los objetivos de ese juego que es la vida, para que estuviera conforme a la mirada de ese observador. Pero nadie superior nos ve y todo lo que ocurre en nuestra vida sucede sin un porqué. (Vila-Matas 1997: 148)

Otra estrategia literaria que reflejaría esta crisis del sujeto sería la creación de personajes escindidos a los que vemos viajar de un sitio a otro, siempre en tránsito, continuamente en casa y a la vez lejos de ésta. Su odisea no sería circular, sino vertical, y reflejaría, como escribe el propio Vila-Matas en El viaje vertical, una «excepcional capacidad para hundirse» (1999: 242).

La creación de narradores poco fiables y la construcción de personajes fragmentarios no constituyen las únicas estrategias literarias que reflejan la crisis del sujeto moderno. Podemos mencionar un tercer procedimiento que aparece en obras como Bartleby y compañía (2000), El mal de Montano (2002) y Doctor Pasavento (2005) y que consistiría en la tematización del silencio. En Bartleby $y$ compañía, por ejemplo, el narrador se dedica a rastrear la historia de los escritores que decidieron desaparecer, seres excéntricos que caen paralizados por la «pulsión del No» que atraviesa las letras contemporáneas. Vila-Matas elabora así toda una poética del silencio, un tratado sobre los autores que han suprimido al sujeto del horizonte del texto, como Mallarmé, Rimbaud o Rulfo.

Por otro lado, en Doctor Pasavento, el narrador protagonista viajará al castillo de Montaigne en Burdeos para encontrar las raíces del sujeto moderno ilustrado. Sin embargo, hallará una revelación sorprendente: descubrirá que, en contra del sueño kantiano, el sujeto es precisamente lo que no puede sujetarse, pues su naturaleza es pasar y pasear. Pasavento encarnará dicha revelación.

\section{Aire de todas las máscaras}

Antes de abordar la utilización que hace Vila-Matas del teatro para pensar un mundo en crisis, digamos unas palabras sobre el argumento y los temas que

8 Me refiero a El grado cero de la escritura (Barthes 1973) y a El espacio literario (Blanchot 1992). 
trata Aire de Dylan. Publicada en 2012, el narrador de esta novela es un personaje vila-matiano típico, pues se trata de un escritor que desea dejar de escribir y que acude a un congreso, organizado en la Universidad de San Gallen, en Suiza, sobre un tema inquietante: el fracaso. Allí conoce a Vilnius, un joven cineasta al que también han invitado a participar. Y es en este congreso donde conoce la historia de este nuevo Príncipe de Dinamarca.

En claro paralelismo con Hamlet, Aire de Dylan trata sobre los acontecimientos que suceden tras la muerte de Lancastre, un escritor consagrado que supuestamente ha sido asesinado por su amigo Claudio, quien además es el amante de su viuda, Laura Verás. El fantasma de Lancastre se le aparece a su hijo -el joven Vilnius al que nuestro narrador conoce en Suiza- para revelarle la verdad de su muerte y reclamar venganza:

Mi padre estaba muerto, pero no podía olvidarme de que muchos difuntos, según una creencia popular, permanecen en la Tierra durante un tiempo antes de marcharse definitivamente.

- ¿Hamlet?

¡Hamlet! ¿Había dicho Hamlet? ¡Eso sí que era ya una extravagancia! ¿Por qué ese cambio de Vilnius a Hamlet? ¿Qué pretendía ese «algo»? (Vila-Matas 2012: 29)

Como es habitual en su producción, en Aire de Dylan Vila-Matas se apropia de un texto del pasado para leerlo en clave metaliteraria. Es decir, que no sólo dialoga con él en tanto que ficción, sino también en tanto que texto que nos hablaría de la naturaleza misma de la ficción literaria. Así, por ejemplo, el tema hamletiano de la relación filial padre-hijo, Vila-Matas lo transforma en el tema de la influencia literaria entre distintas generaciones de autores, lo que da lugar a toda una reflexión sobre la formación del canon literario. O el tema de la posteridad del héroe, que en Hamlet aparece planteado en la petición que, en la última escena, le hace el Príncipe a Horacio de que le sobreviva para contar su historia ${ }^{9}$, Vila-Matas lo transforma a su vez en el tema de la posteridad del escritor.

Pero retomemos ahora el hilo conductor de estas páginas: la utilización que hace Vila-Matas del teatro para pensar un mundo y un sujeto en crisis. Merece la pena empezar recordando que unos años antes de que apareciera Aire de Dylan, ya hallamos formulada la tópica de «el mundo es un teatro» en Dietario voluble, un libro publicado en 2008:

El mundo es una ilusión, un escenario en el que todos tenemos frases que decir y un papel que representar. Cierta clase de actores, al reconocer que están en una obra, seguirán actuando a pesar de todo; otra clase de actores, escandalizados de descubrir que están participando en una mascarada, tratarán de irse del escenario y de la obra. Los segundos se equivocan. (Vila-Matas 2008: 171. El subrayado es mío)

9 «HAMLET.- ¡Oh buen Horacio! ¡Qué nombre más execrable me sobrevivirá, de quedar así las cosas ignoradas! Si alguna vez me albergaste en tu corazón permanece ausente de esa bienaventuranza, y alienta por cierto tiempo en la fatigosa vida de este mundo de dolor para contar mi historia.» (Shakespeare 2012: 232). 
Como vemos, en este fragmento no sólo aparece empleada una de las metáforas del teatro, sino las tres que componen la tópica, lo que hace que la imagen tenga un alcance triple: el mundo es un teatro; la vida es una representación teatral; y el ser humano es un actor que representa un papel. Estas tres figuras vehiculan la imagen de un mundo en crisis en el que distinguir lo real de sus apariencias es imposible e inútil, pues tal distinción no existe. Por ello, el narrador nos previene de lo superfluo que resultaría tratar de salir del escenario, pues fuera de él no hay nada:

[...] fuera del teatro no hay nada, ninguna vida alternativa a la que uno pueda incorporarse. El espectáculo, al igual que el teatro kafkiano de Oklahoma, es, por así decirlo, el único que hay en la cartelera. Y lo único que uno puede hacer es seguir representando su papel, aunque tal vez con una nueva conciencia, una conciencia cómica. (Vila-Matas 2008: 171)

En Aire de Dylan, estas metáforas del hombre-actor y de la vida como representación teatral se emplean desde el comienzo de la novela: «Algunos entran muy tarde en el teatro de la vida, pero cuando lo hacen parece que entren sin brida y directos hasta el final de la obra» (p. 13). Y, más adelante, la metáfora que ya he citado al inicio de este artículo - «iLa vida es una farsa que todos debemos representar?» (p. 313)- se repite en distintas ocasiones ${ }^{10}$. Estas figuras redundan en la idea que se planteaba ya en Dietario voluble, a saber, que el sujeto moderno trascendental, capaz de constituir un mundo estable, ha entrado en crisis. El teatro es la herramienta idónea para pensar dicho mundo desquiciado, pues su naturaleza es en sí misma fantasmagórica. Como escribe Georges Banu en Amour et désamour du théâtre: «Le théâtre sévanouit, il fuit et il nous laisse les mains vides. Mais, du théâtre on ne peut se séparer car il est ombre du monde et du moi. Ombres réciproques, la salle de la scène et inversement.» (Banu 2013: 152).

Por otro lado, y al igual que sucede en Hamlet, en Aire de Dylan también encontramos el recurso de la recreación de una representación teatral. Recordemos que en la obra magna de Shakespeare, Hamlet duda de la palabra del fantasma y para ponerle a prueba -para probar la verdad de su revelación pero también, podemos suponer, la verdad del propio fantasma- se le ocurre utilizar el teatro como ardid. Así, Hamlet les pide a los cómicos de la ciudad que representen la obra "El asesinato de Gonzago» y que introduzcan unos versos apócrifos, que él mismo escribe, donde precisamente se representa el asesinato de un rey. Así, al ver la reacción de Claudio - si se da por aludido o no- Hamlet podrá probar la verdad del fantasma:

10 Por razones de espacio nuevamente me resulta imposible recoger todos los ejemplos que encontramos en la novela. Sirva este fragmento como muestra: «Vilnius sonrió al ver lo mal que arrojaba aquellos residuos, y yo, por mi parte, no pude evitar mirarle con cierta compasión, porque me acordé de que, si la historia de nuestras vidas seguía casualmente una fatal mecánica teatral interna él podía convertirse -como príncipe que era de la historia- en la próxima víctima.» (2012: 322). 
HAMLET -[...] He oído contar que personas delincuentes, asistiendo a un espectáculo teatral, se han sentido a veces tan profundamente impresionadas por el solo hechizo de la escena, que en el acto han revelado sus delitos [...]. El espíritu que he visto bien podría ser el diablo [...] Quiero tener pruebas más seguras. ¡El drama es el lazo con el que cogeré la conciencia del rey! (Shakespeare 2012: 103-104)

Vilnius y Débora -la Ofelia vila-matiana- tampoco están muy convencidos de que el fantasma haya dicho la verdad sobre la muerte de Lancastre. Por eso también deciden ponerle a prueba a través del teatro y, en la quinta parte de la novela, escenifican su propio Teatro de ratonera, que rememora el título que Hamlet puso a su creación:

Con su Teatro de ratonera les guiaba a los dos, a Débora y a Vilnius, el convencimiento de que la ficción siempre servirá mucho mejor para decir o insinuar la verdad que otros medios que se han revelado ineficaces. [...] Como no tenían Vilnius y Débora prueba alguna del crimen, aquélla había sido la mejor forma de propagar el rumor, de lanzar el infundio que tal vez acabaría no teniendo nada de calumnia. (Vila-Matas 2012: 180-192)

Como a Hamlet, la idea que les mueve al difundir el rumor de que Claudio ha asesinado a Lancastre es probar la verdad del fantasma, lo que propicia nuevos guiños llenos de humor a la obra de Shakespeare:

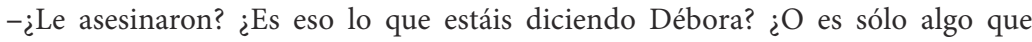
se inventó Lancastre para sus memorias?- preguntó Vilnius siguiendo el plan establecido.

-Eso iban a decir sus memorias narradas y eso dicen las que estoy restaurando yo y desde no hace mucho lo dice también el espectro -dijo Débora.

-¿Qué espectro? -interrumpió el socio 4.

$-¿$ Qué espectro? -preguntó Montse.

-Y bueno, por favor, ¿no han visto ustedes nunca Hamlet? ¡Y qué espectro va a ser! -dijo Débora. (Vila-Matas 2012: 192)

Al jugar con la ilusión mimética y los niveles de ficción, el recurso de la representación teatral subraya la crisis ontológica y epistemológica que envuelve al sujeto contemporáneo. Una idea que se ve reforzada por la continua defensa de la máscara que también encontramos en la novela:

Lancastre [...] le recomendó que huyera de lo auténtico, pues si algún placer había en el cine o en cualquier otro arte, ése no era otro que el placer de poder andar por ahí disfrazado.

-Interpretar un personaje -concluyó su padre-. Hacerte pasar por lo que no eres. Fingir. El irónico y taimado carnaval. La gran fiesta de la astucia y de la mascarada. Algún día lo comprenderás. (p. 278)

José María Pozuelo Yvancos, uno de los críticos españoles que más atención ha dedicado a Vila-Matas, ha explicado con lucidez cómo esta poética de la mascarada está al servicio de la construcción de personajes que no poseen una identidad estable sino que cambian continuamente:

El tema del doble, de la personificación y de la máscara, no hay género que lo diga mejor que el teatro. En la novela aparece representado otro personaje real, Mario 
Gas, conocido director teatral amigo del narrador, quien le invita a dar el salto en el teatro, consciente quizá de la continua teatralización llevada a cabo en sus escenas (en la ponencia de Vilnius y sus interrupciones, sin ir más lejos). El teatro aparece otra vez de manera directa tanto en las alusiones a Hamlet y las veces que Juan Lancastre se aparece al hijo llamándole así, como en la representación «Teatro de ratonera». Pero de manera radical lo está en lo que podríamos llamar una poética del personaje mutante, que el narrador reconoce que le asalta de continuo, al haberse representado en muy diferentes figuraciones, aunque concluye irónicamente: «Si Dios no tiene unidad, cómo la voy a tener yo.» (p. 46). (Pozuelo Yvancos 2013: 216).

Además de las metáforas teatrales, la recreación de una representación teatral y la defensa de la máscara, la novela emplea el teatro también en otro sentido. Me refiero a lo que podemos llamar la «teatralización del acto de escribir», un recurso muy original que por otro lado caracteriza gran parte de la producción de Vila-Matas. En efecto, como apunta Pozuelo Yvancos, en distintas partes de la obra aparecen situaciones muy teatrales -como la conferencia que pronuncia Vilnius en Suiza- vinculadas al acto de escribir:

El joven Vilnius fue leyendo su relato casi como si fuera una obra de teatro radiofónico, lo cual en el fondo no dejaba de tener su sentido, pues a fin de cuentas las intervenciones de aquel Congreso del fracaso eran grabadas íntegramente por Radio Zurich y, además, el relato que Vilnius leyó invocaba al teatro en su título. (Vila-Matas 2012: 16)

Como digo, esta tendencia a escenificar el acto de creación y recepción literaria es común en la narrativa de Vila-Matas. Tanto es así que, incluso, ha dado lugar a un género literario nuevo, al que podría denominarse "conferencia ficcional». En efecto, en novelas como El mal de Montano, París no se acaba nunca (2003) o Doctor Pasavento, por citar sólo algunos ejemplos, el narrador -que suele identificarse como autor metaficcional de las páginas que leemosacude a una conferencia para leer y a veces incluso crear en vivo y en directo un texto. Sirva a modo de ejemplo este fragmento de El mal de Montano:

Llevo ya varios días, señoras y señores, distinguido público húngaro, en esta melancólica y bella ciudad de Budapest, llegué a ella con tiempo más que suficiente para dedicarme a preparar in situ esta conferencia enmarcada en este Simposio Internacional sobre el Diario Personal como Forma Narrativa. (VilaMatas 2002: 207)

A mi modo de ver, esta propensión a arraigar el acto de creación y recepción literaria en un escenario teatral participa del "giro performativo» posmoderno que, a partir de los años sesenta del siglo pasado, caracteriza numerosas artes, no sólo las propiamente escénicas. Según Erika Fischer Lichte, crítica alemana que ha teorizado dicho giro:

[...] las artes visuales, la música, la literatura o el teatro tienden a partir de entonces a llevarse a cabo en y como realizaciones escénicas. En lugar de crear obras, los artistas producen cada vez más acontecimientos en los que no están involucrados sólo ellos mismos, sino también los receptores, los observadores, los oyentes y los espectadores. (2011: 45) 
En este sentido, la predilección por una escritura emplazada en el «aquí y el ahora» que muestra a menudo Vila-Matas en sus obras procedería de su comprensión de ésta como acontecimiento abierto al azar y a la contingencia. Se trata, sin duda, de una actitud posmoderna que, de nuevo, dejaría entrever la crisis ontológica y epistemológica del sujeto, pues si antes veíamos que el teatro era una forma metafórica de nombrar la imposibilidad -y la inutilidad- de distinguir lo real y sus apariencias, ahora la escenificación de la escritura querría subrayar el carácter contingente e inesperado de toda creación literaria. Desde este punto de vista, el sujeto -el escritor, el autor- no sólo sería incapaz de constituir un mundo estable sino que tampoco podría prever los efectos que producirá aquello que crea. Escribir sería entonces un acontecimiento performativo imposible de controlar, programar o calcular, pues, como ha señalado Joseph Danan, lo que persigue una performance es, precisamente, producir una acción que esté lo más viva posible en el presente no reproducible de la representación (Danan 2013: 23).

Así pues, podemos concluir que todo Aire de Dylan está recorrido por el fantasma del teatro, pues los niveles de teatralidad se multiplican según vamos avanzando en el análisis: las metáforas teatrales, la multiplicación de los niveles diegéticos a partir de la incorporación de una representación de teatro, la defensa de la máscara, la reescritura en clave metaliteraria de Hamlet y la escenificación del acto de creación literaria son estrategias que, en definitiva, se ponen al servicio de una imagen del mundo y del sujeto en crisis.

\section{La verdad del fantasma}

Harold Bloom, uno de los mejores conocedores de la obra de Shakespeare de nuestro tiempo, desarrolla en distintos lugares (Bloom 1998: 383-431; 2000: 243263) una idea a propósito de Hamlet que considero muy acertada para cerrar estas páginas. Según este crítico norteamericano, es difícil encontrar una obra anterior a ésta que esté más obsesionada por el teatro. De hecho, por momentos parece que Shakespeare hubiera querido ahogar al público del Globe en teatralidad, pues de forma inesperada, los espectadores que acudieron a la representación asistieron al drama más experimental jamás montado, nada menos que cuatro obras en una, con asombrosos interludios sobre el arte del teatro (Bloom 2000: 255). Una representación cuyos niveles de teatralidad son tan infinitos como la conciencia y las dudas del propio Príncipe.

Como hemos visto, también Aire de Dylan es una novela obsesionada por el teatro y lo teatral. Una obsesión que, como en la tragedia a la que rinde homenaje, se pone al servicio de una visión barroco-posmoderna del mundo en la que lo real y sus apariencias son indiscernibles. En todo caso, esta obsesión por lo teatral que encontramos en ambas obras no sólo responde a la utilización de este arte como herramienta para pensar un mundo en crisis. Su alcance tiene, si cabe, mayor envergadura, pues ambas emplean la reflexión sobre el teatro para pensar metonímicamente la naturaleza ontológica de toda obra de arte. En otras palabras: Hamlet y Aire de Dylan tratan de probar la verdad del fantasma 
fantasma, que no es otra que la verdad del arte. Muestran, en definitiva, que quien va al teatro o lee una novela sin duda cree, o quiere creer, en los fantasmas ${ }^{11}$.

Terminaré planteando unos últimos interrogantes. ¿Cuál es la verdad del fantasma? ¿Qué «régimen de verdad» inaugura una obra de arte? ¿Cuál es, en definitiva, la naturaleza ontológica de lo estético, ese reino de las apariencias poblado de fantasmas?

Sin duda, la verdad del fantasma no es la verdad absoluta con la que soñaba el sujeto trascendental de la modernidad. Seguramente se trate de una verdad muy diferente: la verdad de las sombras, de los espejos y de los sueños... Materia efímera y aérea de la que estamos hechos, pues como leemos al final de Aire de Dylan en un último homenaje a Shakespeare: «ese aire [...] es la materia de la que estamos hechos, leve viento de vida y muerte, aire de todas las máscaras, aire de Dylan» (p. 325) ${ }^{12}$.

\section{Bibliographie}

Banu, G., 2013, Amour et désamour du théâtre, Paris, Actes Sud.

Barthes, R., 1973, El grado cero de la escritura, Buenos Aires, Siglo XXI.

Blanchot, M., 1992, El espacio literario, Barcelona, Paidós Ibérica.

Bloom, H., 1998, Shakespeare. The Invention of the Human, Nueva York, Riverhead Books.

Bloom, H., 2000, Cómo leer y por qué, Santafé de Bogotá, Norma.

Capriolo, P., 1995, La spettatrice, Milán, Bompiani.

Chalandon, S., 2013, Le quatrième mur, Paris, Grasset.

Curtius, E.-R., 1999, Literatura europea y Edad Media Latina, 2 vols., Madrid, Fondo de Cultura Económica de España.

Danan, J., 2013, Entre théâtre et performance: la question du texte, Arles, Actes Sud.

Deleuze, G., Guattari, F., 1993, ¿Qué es filosofía?, Barcelona, Anagrama.

Fischer-Lichte, E., 2011, Estética de lo performativo, Madrid, Abada Editores.

Gopegui, B., 1995, Tocarnos la cara, Barcelona, Anagrama.

Greenblatt, S., 2001, Hamlet in Purgatory, Princeton, Princeton University Press.

11 En un libro fascinante, titulado Hamlet in Purgatory (2001), Stephen Greenblatt desarrolla esta relación entre el teatro Shakesperiano y el culto a los muertos que encontramos también en diferentes tradiciones.

12 Esta vez la cita procede de La tempestad, donde en el cuarto acto PróSPERo advierte que « Nuestros festejos han terminado. Estos actores nuestros/, como te avisé, eran todos espíritus, $\mathrm{y} / \mathrm{se}$ han fundido en el aire, en sutil aire/, y, como la tela sin cimiento de esta visión/, las torres coronadas de nubes, los espléndidos palacios/, los solemnes templos, y la misma gran esfera/, con todo lo que le pertenece, se disolverá, y, como este efímero espectáculo, no dejará rastro alguno. Estamos hechos de la misma sustancia de la que están hechos los sueños/, y nuestra pequeña vida se encierra en un sueño. » (Shakespeare 2010). 
Hutcheon, L., 1990, A Poetics of Postmodernism: History, Theory, Fiction, Londres / New York, Routeledge.

Jameson, F., 1991, El posmodernismo o la lógica cultural del capitalismo avanzado, Barcelona, Paidós.

Jarauta, F., 1986, «De la razón clásica al saber de la precariedad», in: La crisis de la razón, Francisco Jarauta, dir., Murcia, Universidad de Murcia.

Lipovetsky, G., 2004, La era del vacío, Barcelona, Anagrama.

Magrinyà, L., 2000, Los dos luises, Barcelona, Anagrama.

McHale, B., 1996, Postmodernist fiction, Londres / New York, Routeledge.

Molina-Foix, V., 2012, «Prólogo. La edad de Hamlet», in: Hamlet, Madrid, Alianza Editorial.

Oñate, Zubía, 1987, "Al final de la modernidad», Los cuadernos del Norte, 43, p. $40-46$.

Ordóñez, M., 2002, Comedia con fantasmas, Barcelona, Plaza y Janés.

Pavis, P., 2006, Dictionnaire du théâtre, Paris, Armand Colin.

Pozuelo Yvancos, J.-M., 2013, "Aire de Dylan: Vila-Matas frente al espejo literario», Boletín Hispánico Helvético, 22, p. 211-223.

Shakespeare, W., 2010, La tempestad, Madrid, Cátedra.

Shakespeare, W., 2012, Hamlet, Madrid, Alianza Editorial.

Vila-Matas, E., 1973, Mujer en el espejo contemplando el paisaje, Barcelona, Tusquets.

Vila-Matas, E., 1977, La asesina ilustrada, Barcelona, Tusquets.

Vila-Matas, E., 1985, Historia abreviada de la literatura portátil, Barcelona, Anagrama.

Vila-Matas ,E., 1997, Extraña forma de vida, Barcelona, Anagrama.

Vila-Matas, E., 1999, El viaje vertical, Barcelona, Anagrama.

Vila-Matas, E., 2000, Bartleby y compañía, Barcelona, Anagrama.

Vila-Matas, E., 2002, El mal de Montano, Barcelona, Anagrama.

Vila-Matas, E., 2003, París no se acaba nunca, Barcelona, Anagrama.

Vila-Matas, E., 2005, Doctor Pasavento, Barcelona, Anagrama.

Vila-Matas, E., 2008, Dietario voluble, Barcelona, Anagrama.

Vila-Matas, E., 2012, Aire de Dylan, Barcelona, Seix Barral. 